\title{
CUGC for lysinuric protein intolerance (LPI)
}

\author{
Diego Martinelli $\mathbb{C}^{1} \cdot$ Manuel Schiff $\left(\mathbb{C}^{2,3} \cdot\right.$ Michela Semeraro ${ }^{1} \cdot$ Emanuele Agolini $\mathbb{C}^{4} \cdot$ Antonio Novelli ${ }^{4}$ \\ Carlo Dionisi-Vici ${ }^{1}$
}

Received: 31 May 2018 / Revised: 3 March 2020 / Accepted: 10 March 2020 / Published online: 6 April 2020

(c) European Society of Human Genetics 2020

\section{Disease characteristics}

\subsection{Name of the disease (synonyms)}

Lysinuric protein intolerance (LPI).

\subsection{OMIM\# of the disease}

222700.

\subsection{Name of the analysed genes or DNA/ chromosome segments}

SLC7A7 gene.

\subsection{OMIM\# of the gene(s)}

603593.

\subsection{Mutational spectrum}

Lysinuric protein intolerance (LPI) is a rare inborn metabolic disease caused by recessive affecting-function variants in

Supplementary information The online version of this article (https:// doi.org/10.1038/s41431-020-0617-9) contains supplementary material, which is available to authorized users.

Diego Martinelli

diego.martinelli@opbg.net

1 Division of Metabolism and Research Unit of Metabolic Biochemistry, Bambino Gesù Children's Hospital, IRCCS, Rome, Italy

2 Fédération de Génétique Médicale, Hôpital Necker Enfants Malades, Paris, France

3 UMR1163, Université Paris Descartes, Sorbonne Paris Cité, Institut IMAGINE, Paris, France

4 Molecular Genetics Laboratory, Bambino Gesù Children's Hospital, IRCCS, Rome, Italy
SLC7A7 localized to chromosome 14q11.2, encoding the cationic amino acids (CAAs) transporter subunit y+LAT1 $[1,2]$. This subunit is the catalytic light chain subunit of a complex belonging to the heterodimeric amino acid transporter family. From 1999 to March 2020, 69 SLCA7 affectingfunction variants have been identified as causative of LPI [1-8]. Public lists of disease-causing variants can be found on several gene variant databases (see below). However, as it is not available in the literature a complete up-to-date list of diseasecausing variants for $S L C 7 A 7$, we included this information as a Supplementary Excel sheet (See Supplementary Material File \# 1): this list was created by using LOVD and ClinVar databases and linked to the relevant literature reference. Most affecting-function variants reported in these studies are private, except for the Finnish founder variant c.895-2A $>\mathrm{T}$ found in 38 individuals, the c.726G $>\mathrm{A}$ variant found in 13 subjects, and the c. $1228 \mathrm{C}>\mathrm{T}$ variant found in persons of Japanese heritage and one of Moroccan origin. All types of affecting-function variants have been reported: missense and nonsense variants, deletions, insertions, splicing variants, and large genomic rearrangements. There is no clear genotype/phenotype correlation.

A small proportion of patients ( 5\%) with clinical and biochemical features of LPI do not have SLC7A7 variants detectable on Sanger sequencing [9], suggesting the presence of uncommon SLC7A7 variants such as deep intronic variants or large intragenic deletions/duplications.

\subsection{Analytical methods}

Sequencing of all coding exons and intron-exon boundaries of SLC7A7 by Sanger sequencing, as part of a targeted gene panel for Mendelian syndromes, or by exome or whole-genome sequencing. Exon or whole-gene deletions/duplications may be identified by diverse methods including quantitative PCR, long-range PCR, multiplex ligation-dependent probe amplification, and chromosomal microarray that include this gene/chromosome segment.

Sequence variants are described following HGVS nomenclature guidelines (http://www.hgvs.org/) relative to the NCBI reference sequence. 


\subsection{Analytical validation}

Sanger sequencing is predicted to detect $>99 \%$ of variants in the targeted regions.

There are several steps in the analytical validation process:

- Sequencing of both DNA strands (forward and reverse) is performed.

- When the genetic test is positive, a search of the molecular defects is warranted on a second independent sample from the patient.

Moreover, segregation analysis in the affected proband's relatives provides additional confirmation of the result.

For other sequencing methods, sensitivity will depend on the characteristics of the test, including coverage of the coding regions and intron-exon boundaries, read depth and sequencing quality.

- Numerous databases listing benign and pathogenic variations, such as ClinVar, LOVD, dbSNP, HGMD, 1000 Genomes, EVS, and ExAC may be used to search for novel variants. Pathogenicity of variants is often tested by functional studies or in silico prediction methods using SIFT (La Jolla, CA, USA), Polyphen-2 (Boston, MA, USA) and Mutation Taster softwares (Berlin, Germany).

\subsection{Estimated frequency of the disease (incidence at birth ("birth prevalence") or population prevalence. If known to be variable between ethnic groups, please report)}

LPI has been described sporadically worldwide and has a higher incidence in Finland $(1 / 60,000)$ and in Japan $(1 / 57,000)$.

\subsection{Diagnostic setting}

\begin{tabular}{lcc}
\hline & Yes & No \\
A. (Differential) diagnosis & $\bigotimes$ & $\square$ \\
B. Predictive Testing & $\bigotimes$ & $\square$ \\
C. Risk assessment in Relatives & $\bigotimes$ & $\square$ \\
D. Prenatal & $\bigotimes$ & $\square$ \\
\hline
\end{tabular}

Comment: Variant analysis is mainly used for confirmation of a clinical diagnosis and for genetic counseling. Preimplantation genetic diagnosis (PGD) may be offered to affected families with confirmed variants affecting protein function but its availability depends on the healthcare system regulations in their country.

\section{Test characteristics}

\begin{tabular}{|c|c|c|c|c|}
\hline \multirow{3}{*}{ 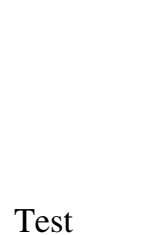 } & \multicolumn{2}{|c|}{$\begin{array}{l}\text { Genotype } \\
\text { or disease }\end{array}$} & \multirow{2}{*}{$\begin{array}{l}\text { A: True } \\
\text { positives } \\
\text { B: False } \\
\text { positives }\end{array}$} & \multirow{2}{*}{$\begin{array}{l}\text { C: False } \\
\text { negative } \\
\text { D: True } \\
\text { negative }\end{array}$} \\
\hline & & Absent & & \\
\hline & \multicolumn{4}{|c|}{ Test } \\
\hline Positive & A & B & $\begin{array}{l}\text { Sensitivity: } \\
\text { Specificity: }\end{array}$ & $\begin{array}{l}\mathrm{A} /(\mathrm{A}+\mathrm{C}) \\
\mathrm{D} /(\mathrm{D}+\mathrm{B})\end{array}$ \\
\hline \multirow[t]{2}{*}{ Negative } & $\mathrm{C}$ & D & $\begin{array}{l}\text { Positive predictive } \\
\text { value: }\end{array}$ & $\mathrm{A} /(\mathrm{A}+\mathrm{B})$ \\
\hline & & & $\begin{array}{l}\text { Negative } \\
\text { predictive value: }\end{array}$ & $\mathrm{D} /(\mathrm{C}+\mathrm{D})$ \\
\hline
\end{tabular}

\subsection{Analytical sensitivity}

(proportion of positive tests if the genotype is present) Sequence analysis: nearly $95 \%$.

\subsection{Analytical specificity}

(proportion of negative tests if the genotype is not present)

Sequence analysis: nearly $95 \%$.

\subsection{Clinical sensitivity}

\section{(proportion of positive tests if the disease is present)}

The clinical sensitivity can be dependent on variable factors such as age or family history. In such cases a general statement should be given, even if a quantification can only be made case by case.

Clinical sensitivity in cases of LPI where the clinical and biochemical phenotype is present is likely to be very high; the absence of a positive result is likely to be related to the analytical sensitivity. Notably, some patients may show an incomplete biochemical phenotype. In some individuals, the diagnosis is established in adulthood, because of milder symptoms due to spontaneous avoidance of dietary protein. These cases can likely result in a lower sensitivity.

\subsection{Clinical specificity}

(proportion of negative tests if the disease is not present)

The clinical specificity can be dependent on variable factors such as age or family history. In such cases a general statement should be given, even if a quantification can only be made case by case. 
Given the presence of characteristic clinical picture and almost invariably present metabolic abnormalities, clinical specificity is close to $100 \%$. Late onset paucisymptomatic LPI cases can lower clinical specificity.

\subsection{Positive clinical predictive value}

\section{(life time risk to develop the disease if the test is positive)}

Although the onset of symptoms is in most cases in infancy, the diagnosis is sometimes delayed, as classic symptoms of LPI may be unnoticed during the first and second decades of life because of selective avoidance of dietary protein. In some cases, the diagnosis is established in adulthood. Genetic analysis does not have a prognostic value, due to the lack of a clear genotype-phenotype correlation.

\subsection{Negative clinical predictive value}

(probability not to develop the disease if the test is negative)

Assume an increased risk based on family history for a non-affected person. Allelic and locus heterogeneity may need to be considered.

Index case in that family had been tested:

The negative clinical predictive value is likely to be $100 \%$ if the index case in the family had been tested and was found positive for $S L C 7 A 7$ variants.

Index case in that family had not been tested:

Unknown but probably high due to consistent biochemical abnormalities.

\section{Clinical utility}

\section{1 (Differential) diagnostics: The tested person is clinically affected}

(To be answered if in 1.9 "A" was marked)

\subsubsection{Can a diagnosis be made other than through a genetic test?}

\begin{tabular}{lll}
\hline No & $\square$ (continue with 3.1.4) & \\
Yes & $\bigotimes$ & $\square$ \\
& Clinically & $\bigotimes$ \\
& Imaging & $\square$ \\
& Endoscopy & \\
\hline
\end{tabular}

Table (continued)

\begin{tabular}{ll} 
Biochemistry & $\bigotimes$ \\
Electrophysiology & $\square$ \\
Other (please describe) & Immunology tests x \\
\hline
\end{tabular}

Comment: LPI diagnosis is usually based on clinical and biochemical findings. Nausea and vomiting after protein ingestion, failure to thrive, hepatomegaly, and splenomegaly are typical clinical features [1]. Patients can also exhibit lung, kidney, hematologic, musculoskeletal, and/or neurological involvement with an extreme clinical variability [10] and are highly predisposed to develop interstitial lung disease and/or pulmonary alveolar proteinosis (PAP) [10]. Growth retardation, delayed puberty, and skeletal abnormalities (multiple fractures, idiopathic osteoporosis, and short stature) are possible complications [10]. LPI patients show frequently hematological/immunological abnormalities, with anemia, thrombocytopenia, leukopenia, systemic autoimmune diseases, and increased susceptibility to hemophagocytic lymphohistiocytosis (HLH). In LPI, subclinical HLH is a highly frequent finding with increased serum LDH, ferritin, and triglycerides and provides a very useful clue to the diagnosis for the clinician. HLH is characterized by excessive activation and proliferation of $\mathrm{T}$ lymphocytes and macrophages with massive hypersecretion of proinflammatory cytokines [11]. In LPI, efflux of the dibasic CAAs lysine, arginine, and ornithine (system $\mathrm{y}+\mathrm{L}$ ) is defective at the basolateral membrane of epithelial cells in the renal tubules and small intestine [12]. Huge amounts of lysine and more moderate amounts of arginine and ornithine are lost in the urine, with a limited intestinal absorption, justifying their low plasma levels. Glutamine, glycine, alanine and, especially, citrulline concentrations in blood are often secondarily elevated due to urea cycle (UC) dysfunction. Citrulline is elevated also at birth and it is sometimes detectable by newborn screening. Hyperammonemia with subsequent neurologic consequences (from moderate acute encephalopathy to coma) after protein ingestion and potential diminished protein tolerance in LPI resemble the symptoms of UC defects. UC dysfunction in LPI is best explained by functional deficiency of the intermediates arginine and ornithine in the hepatocytes due to their defective efflux. Deficiency of arginine, the rate-limiting precursor of NO synthesis, in blood, and intracellular accumulation, can alter NO concentrations, affecting vascular and immunological functions [13]. Recently, an impairment of system $\mathrm{y}+\mathrm{L}$ in monocytes and alveolar macrophages in LPI [14], as well as an impairment of arginine influx/efflux through system $\mathrm{y}+\mathrm{L}$ in LPI macrophages, with secondary defect of phagocytic activity were described, suggesting a pathogenic role of these cells in 
the development of LPI-associated complications [15]. Other laboratory abnormalities include anemia, thrombocytopenia, or even pancytopenia associated with hypofibrinogenemia, low levels of haptoglobin, and high plasma levels of LDH, ferritin, and triglycerides, as part of the picture of a macrophage activating syndrome (MAS). Orotic aciduria reflects the UC dysfunction.

Proximal renal tubular dysfunction may be observed in infants, while chronic renal failure with glomerular dysfunction is sometimes seen as a long-term complication.

If the genetic diagnosis of LPI has not been confirmed, disorders with similar clinical and biochemical features need to be excluded. Other UC disorders can present with hyperammonemia; however, hyperammonemia with increased orotic aciduria and hyperexcretion of CAAs is characteristic of LPI, making the diagnosis straightforward. Lysosomal storage diseases such as Niemann-Pick disease type B and Gaucher disease can present with hepatosplenomegaly, interstitial lung disease, and hematologic abnormalities. Clinical features as failure to thrive, hepatosplenomegaly, fever, and laboratory abnormalities as hypertriglyceridemia, hypercholesterolemia increased serum ferritin concentration, anemia is also frequent in acquired or familial HLH or MAS. LPI shares also some biochemical findings with autoimmune disorders such as systemic lupus erythematosus.

\subsubsection{Describe the burden of alternative diagnostic methods to the patient}

In typical cases, clinical diagnosis is achieved by combining family history, physical examination and biochemical results, and especially the elevated serum levels of ferritin, LDH, cholesterol, and triglycerides (see above). Sometimes, a better assessment of lung pathology may require a lung CT scan or lung biopsy performed under general anesthesia. Rarely, kidney involvement is studied with a renal biopsy, showing immune-mediated glomerulonephritis as well as chronic tubulointerstitial nephritis with glomerulosclerosis without immune deposits.

\subsubsection{How is the cost effectiveness of alternative diagnostic methods to be judged?}

Unknown. The investigations described above are relatively inexpensive individually. If there is strong clinical suspicion of LPI, the combined expense of biochemical testing, ultrasound, and radiological investigations are comparable with or exceed the cost of primary molecular testing. However, the examinations required for differential diagnosis after exclusion of LPI can be less costeffecting than those based on standard or next-generation sequencing.
3.1.4 Will disease management be influenced by the result of a genetic test?

No

Yes $\square$

Therapy (please Acute treatment in the patients who describe) experienced severe hyperammonemia is similar to other UCDs [16]. Long-term treatment consists of a low-protein diet $(1-1.5 \mathrm{~g} / \mathrm{kg} / \mathrm{day}$ in children and $0.5-0.8 \mathrm{~g} / \mathrm{kg} / \mathrm{day}$ in adults) supplemented with citrulline $(<100 \mathrm{mg} / \mathrm{kg} / \mathrm{day})$, and occasionally arginine or ornithine. Lysine supplementation is controversial. Protein restriction may be combined with sodium benzoate or sodium phenylbutyrate. Careful monitoring of ammonia, amino acid profiles, and orotic acid is necessary to verify individual tolerance and avoid malnutrition.

Prognosis (please Early identification of this disorder describe) is crucial, in order to prevent severe episodes of hyperammonemia that may cause irreversible neurological damage. Late onset complication are less responsive to pharmacological and dietary treatment, but establishing the diagnosis can help to anticipate organ damage through a careful monitoring, ameliorating the overall prognosis.

Management Avoidance of metabolic decom(please describe) pensations, nutritional, management, and prevention of specific complications are the major therapeutic objectives. While hyperammonemia can be efficiently treated, no effective therapy has been established for late and multiorgan complications. For treatment of lung disease, various approaches (high-dose corticosteroid, granulocyte/monocyte colony stimulating factor in patients with PAP) have been tried, without overt clinical benefit. Lung lavage 
Table (continued)

still remains the best therapeutic approach for PAP in LPI, but recently bone marrow transplantation (aimed to correct macrophage defects) have been proposed as a possible treatment [14]. Heart-lung transplantation is contraindicated, as demonstrated by the fatal disease relapse in a transplanted patient [16]. Specific therapies for kidney complications, immunological dysfunction (HLH/MAS), and osteoporosis should be used under the supervision of medical specialists following standardized protocols. Some patients with MAS/glomerulonephritis and autoimmune manifestations responded to immunosuppressive drugs or high-dose immunoglobulin infusion. LPI requires regular life-long surveillance in order to avoid side effects of treatments (i.e., malnutrition and low-intake of essential amino acids) and to diagnose/treat specific organ complications.

\subsection{Predictive Setting: The tested person is clinically unaffected but carries an increased risk based on family history}

(To be answered if in 1.9 "B" was marked)

\subsubsection{Will the result of a genetic test influence lifestyle and prevention?}

If the test result is positive (please describe):

Yes, see 3.1.4.

If the test result is negative (please describe):

Depending on the clinical manifestations in the individual who has been tested.

3.2.2 Which options in view of lifestyle and prevention does a person at-risk have if no genetic test has been done (please describe)?

As diagnosis of LPI is primarily based on clinical and biochemical findings, a high level of suspicion may be enough to start the specific dietary and pharmacological treatment.

\subsection{Genetic risk assessment in family members of a diseased person}

(To be answered if in 1.9 "C" was marked)

3.3.1 Does the result of a genetic test resolve the genetic situation in that family?

Yes; after molecular confirmation in the proband, testing can be offered to other family members as appropriate and the overall family risk can be assessed.

3.3.2 Can a genetic test in the index patient save genetic or other tests in family members?

No, if a disease-causing variant is identified in the index patient, family members should be tested in order to avoid apossible variant's spreading in the adult age.

3.3.3 Does a positive genetic test result in the index patient enable a predictive test in a family member?

Yes.

\subsection{Prenatal diagnosis}

(To be answered if in 1.9 "D" was marked)

3.4.1 Does a positive genetic test result in the index patient enable a prenatal diagnosis?

Yes, prenatal molecular diagnosis can be offered.

\section{If applicable, further consequences of testing}

Please assume that the result of a genetic test has no immediate medical consequences. Is there any evidence that a genetic test is nevertheless useful for the patient or his/her relatives? (Please describe).

The result of the genetic test is used for confirmation of a clinical/biochemical diagnosis in the patient and similarly affected relatives. In addition, a molecular genetic diagnosis may help genotype/phenotype correlations and the planning of future pregnancies/prenatal testing.

Acknowledgements This work was supported by EuroGentest2 (Unit 2: "Genetic testing as part of health care"), a Coordination 
Action under FP7 (Grant Agreement Number 261469) and the European Society of Human Genetics.

\section{Compliance with ethical standards}

Conflict of interest The authors declare that they have no conflict of interest.

Publisher's note Springer Nature remains neutral with regard to jurisdictional claims in published maps and institutional affiliations.

\section{References}

1. Torrents D, Mykkänen J, Pineda M, Feliubadaló L, Estévez R, de Cid R, et al. Identification of SLC7A7, encoding y + LAT-1, as the lysinuric protein intolerance gene. Nat Genet. 1999;21:293-6.

2. Borsani G, Bassi MT, Sperandeo MP, De Grandi A, Buoninconti A, Riboni M, et al. SLC7A7, encoding a putative permeaserelated protein, is mutated in patients with lysinuric protein intolerance. Nat Genet 1999;21:297-301.

3. Sperandeo MP, Andria G, Sebastio G. Lysinuric protein intolerance: update and extended mutation analysis of the SLC7A7 gene. Hum Mutat. 2008;29:14-21.

4. Font-Llitjós M, Rodríguez-santiago B, Espino M, Sillué R, Mañas S, Gómez L, et al. Novel SLC7A7 large rearrangements in lysinuric protein intolerance patients involving the same AluY repeat. Eur J Hum Genet. 2009;17:71-9.

5. Güzel-Ozantürk A, Ozgül RK, Unal O, Hişmi B, Aydın Hİ, Sivri $\mathrm{S}$, et al. Molecular and clinical evaluation of Turkish patients with lysinuric protein intolerance. Gene. 2013;521:293-5.

6. Habib A, Md Yunus Z, Azize NA, Ch'ng GS, Ong WP, Chen BC, et al. Hyperexcretion of homocitrulline in a Malaysian patient with lysinuric protein intolerance. Eur J Pediatr. 2013;172:1277-81.

7. Habib A, Azize NA, Yakob Y, Md Yunus Z, Wee TK. Biochemical and molecular characteristics of Malaysian patients with lysinuric protein intolerance. Malays J Pathol. 2016;38:305-10.

8. Mauhin W, Habarou F, Gobin S, Servais A, Brassier A, Grisel C, et al. Update on lysinuric protein intolerance, a multi-faceted disease retrospective cohort analysis from birth to adulthood. Orphanet J Rare Dis. 2017;12:3.

9. Sebastio G, Nunes V. Lysinuric protein intolerance. In: Pagon RA, Adam MP, Ardinger HH, Wallace SE, Amemiya A, Bean LJH, Bird TD, Ledbetter N, Mefford HC, Smith RJH, Stephens K, editors. GeneReviews $\left({ }^{\oplus}\right)$. Seattle (WA): University of Washington, Seattle; 2006. p. 1993-2017.

10. Ogier de Baulny H, Schiff M, Dionisi-Vici C. Lysinuric protein intolerance (LPI): a multi organ disease by far more complex than a classic urea cycle disorder. Mol Genet Metab. 2012;106:12-17.

11. Duval M, Fenneteau O, Doireau V, Faye A, Emilie D, Yotnda P, et al. Intermittent hemophagocytic lymphohistiocytosis is a regular feature of lysinuric protein intolerance. $\mathrm{J}$ Pediatr. 1999;134:236-9.

12. Palacin M, Borsani G, Sebastio G. The molecular bases of cystinuria and lysinuric protein intolerance. Curr Opin Genet Dev. 2001;11:328-35.

13. Kamada $Y$, Nagaretani $H$, Tamura $S$, Ohama $T$, Maruyama $T$, Hiraoka $\mathrm{H}$, et al. Vascular endothelial dysfunction resulting from L-arginine deficiency in a patient with lysinuric protein intolerance. J Clin Investig. 2001;108:717-24.

14. Barilli A, Rotoli BM, Visigalli R, Bussolati O, Gazzola GC, Kadija Z, et al. In lysinuric protein intolerance system $y+L$ activity is defective in monocytes and in GM-CSF-differentiated macrophages. Orphanet J Rare Dis. 2010;5:32.

15. Barilli A, Rotoli BM, Visigalli R, Bussolati O, Gazzola GC, Gatti $\mathrm{R}$, et al. Impaired phagocytosis in macrophages from patients affected by lysinuric protein intolerance. Mol Genet Metab. 2012;105:585-9.

16. Santamaria F, Brancaccio G, Parenti G, Francalanci P, Squitieri C, Sebastio G, et al. Recurrent fatal pulmonary alveolar proteinosis after heart-lung transplantation in a child with lysinuric protein intolerance. J Pediatr. 2004;145:268-72. 